\title{
Environmental Variables that Ameliorate Extinction Learning Deficits in the 129S1/SvImJ Mouse Strain
}

\author{
V. A. Cazares ${ }^{1}$, G. Rodriguez ${ }^{1}$, R. Parent ${ }^{1}$, L. Ouillette ${ }^{1}$, K. M. Glanowska ${ }^{2}$, S. J. \\ Moore $^{1}$, G.G. Murphy ${ }^{1}$
}

1 Department of Molecular and Integrative Physiology \& Molecular and Behavioral Neuroscience Institute, University of Michigan, Ann Arbor, MI, USA

2 Department of Neurology, University of Michigan, Ann Arbor, MI, USA

Corresponding Authors: Shannon J. Moore \& Geoffrey G. Murphy

\begin{abstract}
:
Fear conditioning is an associative learning process by which organisms learn to avoid environmental stimuli that are predictive of aversive outcomes. Fear extinction learning is a process by which avoidance of fear-conditioned stimuli is attenuated when the environmental stimuli is no longer predictive of the aversive outcome. Aberrant fear conditioning and extinction learning are key elements in the development of several anxiety disorders. The 12951 inbred strain of mice is used as an animal model for maladaptive fear learning because this strain has been shown to generalize fear to other non-aversive stimuli and is less capable of extinguishing fear responses relative to This is the author manuscript accepted for publication and has undergone full peer review but has not been through the copyediting, typesetting, pagination and proofreading process, which may lead to differences between this version and the Version of Record. Please cite this article as doi: $10.1111 / \mathrm{gbb} .12575$
\end{abstract}

This article is protected by copyright. All rights reserved. 
other mouse strains, such as the C57BL/6. Here we report new environmental manipulations that enhance fear and extinction learning, including the ability to discriminate between an aversivelypaired tone and a neutral tone, in both the $129 S 1$ and C57BL/6 strains of mice. Specifically, we demonstrate that discontinuous ('pipped') tone stimuli significantly enhance within-session extinction learning and the discrimination between neutral and aversively paired stimuli in both strains. Furthermore, we find that extinction training in novel contexts significantly enhances the consolidation and recall of extinction learning for both strains. Cumulatively, these results underscore how environmental changes can be leveraged to ameliorate maladaptive learning in animal models and may advance cognitive and behavioral therapeutic strategies.

\section{Introduction:}

Increased probability of survival is associated with an organism's ability to learn when neutral environmental stimuli become predictive of an aversive outcome as is the ability to diminish a fearful response when stimuli no longer predict the aversive outcome (fear extinction). Fear becomes maladaptive when the response to fear stimuli is overgeneralized to other stimuli or when fear responses persist after extinction training. In humans, maladaptive fear or deficits in extinction learning are core features of generalized anxiety disorder (GAD) and post-traumatic stress disorder (PTSD; (Fenster et al. 2018; Milad et al. 2009).

Rodent models of fear learning (i.e. fear conditioning) and fear extinction learning have enriched our understanding of genes and neural circuits involved in the expression of GAD and PTSD symptoms (reviewed in (Fenster et al. 2018). The Pavlovian model of fear conditioning in rodents requires the pairing of a neutral stimulus, such as a tone (conditioned stimulus, CS), with an inherently aversive stimulus (unconditioned stimulus, US) such as a footshock (Pavlov 1927). 
Following one or more CS-US pairings, rodents will typically display a fearful response to the CS alone (conditioned response). Mice respond to fearful stimuli by displaying either passive (freezing) or active (flight) avoidance behavior. Extinction learning is the process by which avoidance of fearful stimuli is diminished through repeated presentation of the CS in absence of the US. Extinction learning involves both forming new associations (Milad \& Quirk 2002; Chhatwal et al. 2005; Herry et al. 2010; Likhtik et al. 2008; H.-C. Lin et al. 2009; Amano et al. 2010; Choi et al. 2010; An et al. 2017) and degradation of the originally learned CS-US pairing (Rescorla \& Wagner 1972; C.-H. Lin et al. 2003; Kim et al. 2007; Dalton et al. 2008; Mao et al. 2013). In humans, extinction learning is a main component of exposure therapy, which is often used in the treatment of PTSD. While this treatment is effective for some, it has very limited success for up to $50 \%$ of the population (Kar 2011), suggesting that further research on extinction-based therapies is needed to improve and individualize treatment options.

Advancements in research show that the propensity for developing PTSD in humans or maladaptive fear in rodents is heritable (Holmes \& Singewald 2013; Logue et al. 2015). Twin studies estimate the heritability of PTSD to range between 40-50\% for humans (Kessler et al. 1995; Afifi et al. 2010; Logue et al. 2015).). In mice, distinct inbred wild-type strains display markedly different fear conditioning and extinction abilities (Holmes \& Singewald 2013). For example, the 129S1 strain is capable of learning and consolidating fear conditioning, but exhibit little to no fear extinction learning or reduced freezing even after mass exposure to an unpaired CS (MacPherson et al. 2013; Whittle et al. 2013). However, 12951 mice do exhibit some extinction learning when exposed to fear conditioning protocols using a weak footshock, yet they are unable to recall learned extinction when tested 24 hours later (Whittle et al. 2013). Moreover, 12951 mice also display greater fear generalization to contexts that are similar but are non-conditioned (Camp et al. 2012; Temme et al. 
2014). In contrast, C57BL/6 mice have repeatedly been shown to exhibit robust fear extinction learning, as evidenced by a significant decrease in freezing behavior after exposure to an unpaired CS (Hefner et al. 2008; Camp et al. 2009; Temme et al. 2014).

Efforts to elucidate the differences in extinction learning between $129 \mathrm{~S} 1$ and C57BL/6 mice have led to a greater understanding of neurophysiological and genetic substrates responsible for the expression and suppression of fear. For example, studies have demonstrated that 129S1 mice have a downregulated hypothalamic-pituitary-adrenal axis (Camp et al. 2012); reduced neural activation in the infralimbic sub-region of the medial prefrontal cortex (Hefner et al. 2008), a brain region critical for modulating extinction learning (Giustino \& Maren 2015); enlarged dendritic arbors in basolateral amygdala (BLA) neurons (Camp et al. 2012); and a greater fraction of parvalbumin-positive inhibitory interneurons expressing perineuronal nets in the BLA (Gunduz-Cinar et al. 2018). The extinction learning deficits in the $129 S 1$ can be ameliorated by dietary zinc restriction (Whittle et al. 2010), deep brain stimulation of the nucleus accumbens (Whittle et al. 2013), pharmacological treatment with the $\alpha 2$-adrenoreceptor antagonist, yohimbine, the selective serotonin reuptake inhibitor, fluoxetine, or the dopamine precursor, L-dopa (Hefner et al. 2008; Camp et al. 2012; Whittle et al. 2016). Interestingly, a recent study used linkage crosses between 12951 and C57BL/6 mice combined with quantitative trait loci analysis to identify a panel of genes in the amygdala that show expression differences which correlate to the extinction learning deficits (Gunduz-Cinar et al. 2018). Of the genes identified, the expression of Ppid, a gene that is functionally coupled to the glucocorticoid receptor, was found to reduce extinction learning deficits in 12951 mice when its expression was increased (Gunduz-Cinar et al. 2018). These data suggest that certain therapeutic interventions can ameliorate the extinction learning deficits that may be genetically encoded in neural circuits of the 12951 mice.

This article is protected by copyright. All rights reserved. 
In the current study, therefore, our research sought to find behavioral approaches that could similarly minimize the extinction deficits in 12951 mice. We found that the use of discontinuous ('pipped') tones ameliorated the extinction learning deficits in 129S1 mice and enhanced the ability of both $129 S 1$ and C57BL/6 mice to discriminate between aversively paired stimuli (CS+) and unpaired or neutral stimuli (CS-). Pipped tones have been commonly used in in vivo neurophysiological studies because they lead to greater neural activation compared with continuous tones (Quirk et al. 1997; Herry et al. 2010; Blair et al. 2005) and enhance stimulus discrimination (Bang et al. 2008; Ito et al. 2009). In addition, we found extinction learning and recall were enhanced when unpaired CS+ presentation (without footshock) occurred in a daily novel context. These two environmental manipulations diminished the 12951 extinction deficits (i.e., fear generalization and fear extinction) to more closely resemble the learning phenotype of the C57BL/6.

This article is protected by copyright. All rights reserved. 


\section{Materials and methods}

\section{Mice}

All mice were obtained from commercial vendors or bred in our colony using naïve mice from the same vendors. Mice were either male or female 129S1/SvImJ obtained from Jackson Laboratories (Stock \# 002448, Bar Harbor, ME), or C57BL/6NTac obtained from Taconic Farms (Model \# B6NTac, Hudson, NY), referred to hereafter as 129S1 and C57BL/6, respectively.

Experiments were conducted using mice aged 9-15 weeks at the time of testing with approximately equal number of males and females ( males $=97$, females $=90$ ). Mice were housed by sex ( 2 to 5 per cage) in micro-isolation cages in a temperature-controlled $\left(22^{\circ} \mathrm{C}\right)$ vivarium with a 14-h/10-h light/dark cycle for a minimum of 4 weeks prior to behavior studies. Mice were provided with ad libitum food and water. All experiments were conducted during the light phase. Prior to fear conditioning, mice were randomly assigned to two groups: US+ (footshocked) and US- (no footshock). Mice in the US+ group received a paired tone (CS+) and a footshock (US+) during fear conditioning. Mice in the US- group were exposed to the same tones but did not receive the paired footshock (US-). The number of mice used in each experiment is given in the figure legends. The Institutional Animal Care and Use Committee of the University of Michigan approved all experiments and guidelines for animal care set by the National Institutes of Health.

\section{Fear conditioning apparatus}

The basic system was as previously described (McKinney \& Murphy 2006; McKinney, Sze, et al. 2008; McKinney, Chow, et al. 2008; Temme \& Murphy 2017). Briefly, fear conditioning 
experiments were conducted in a $27 \times 27 \times 11 \mathrm{~cm}$ chamber with clear acrylic backs and doors, aluminum sides, stainless steel rod floors (rods were spaced $1 / 8$ inches apart), stainless steel drop pans (Med Associates), and overhead lights set at 4 lux. Footshocks were administered through the rods via solid state shock scramblers and electronic constant current shock sources controlled by Actimetrics Freezeframe version 4 software (Wilmette, IL) run on a desktop PC. Actimetrics Freezeframe version 4 software was also used to record behavior using individual cameras mounted above each chamber. Chamber details were altered to create different experimental contexts in some experiments (as indicated in figure legends).

\section{Fear conditioning}

Mice were fear conditioned in Context A for one training session. Context A was assembled using the conditioning chamber described above with the addition of light blue curtains covering the clear acrylic doors, and the clear acrylic backs exposed to the beige walls of the room. In Context A, floor pans and rods were cleaned using $75 \%$ ethanol, and floor pans received 4 sprays of $75 \%$ ethanol to provide a distinct background odor. Mice were individually placed in the conditioning chambers and exposed to Context $A$ for 120 seconds prior to any tone presentation. After the pre-tone period, mice received $5 \mathrm{CS}+\mathrm{US}+$ pairings which consisted of a $25 \mathrm{~s}, 50 \mathrm{~dB}, 4.0 \mathrm{kHz}$ tone that was either continuous or discontinuous ('pipped'). For the pipped tones, each pip lasted for $200 \mathrm{~ms}$ and was presented at $1 \mathrm{~Hz}$ (i.e. 25 total pips). For the US+ groups, both types of tones co-terminated with a $2 \mathrm{~s}, 0.6 \mathrm{~mA}$ footshock. In addition, mice were exposed to 5 unpaired $25 \mathrm{~s}, 50 \mathrm{~dB}$, white noise continuous or pipped tones $\left(\mathrm{CS}^{-}\right)$. The order of $\mathrm{CS}+$ and $\mathrm{CS}^{-}$presentations and the inter-stimulus interval (ISI) were pseudo-randomized (ISI 
duration was between 20 and 180 s). There was a 120 s no-stimulus consolidation period (posttone period) after the final CS+/US pairing before mice were returned to their home cage.

For initial experiments (Figure 1) the tone frequencies of $\mathrm{CS}^{+}$and $\mathrm{CS}^{-}$were counterbalanced. No differences were found in overall freezing or discrimination when assigning $4 \mathrm{kHz}$ or white-noise frequencies to the CS+ (data not graphed, main effect of tone frequency: $\left.F_{(1,37)}=0.45 ; \mathrm{p}=0.51\right)$. Therefore, for the remaining experiments (Figures $\left.2-4\right)$ the $4 \mathrm{kHz}$ tone was assigned to the CS+ while the $\mathrm{CS}^{-}$was composed of white noise.

\section{Extinction training}

After fear conditioning, mice were tested for initial fear recall and within-session fear extinction, which continued over three extinction training sessions (E1, E2, E3), one per day, using a new context. The contexts were organized as follows: Context B consisted of a smooth white acrylic sheet to hide the rod floors, a white curtain covering the clear acrylic doors, a rounded smooth white acrylic wall covering the clear acrylic back, and red light (5 lux); floor pans and rods were cleaned using $2 \%$ acetic acid and floor pans received four sprays of $2 \%$ Acetic Acid to provide a distinct background odor. Context $\mathrm{C}$ consisted of a cloth texture over a smooth acrylic sheet to hide the rod floors, a dark white and blue striped curtain covering the clear acrylic doors, a white cotton sheet covering the clear acrylic backs, and white light (6 lux) provided by floor lamps (instead of overhead lights); floor pans and rods were cleaned using $\mathrm{N}$-acetylcysteine (rotten egg scent) and floor pans received 4 sprays of the rotten egg scent to provide a distinct background odor. Context $\mathrm{D}$ consisted of a grey rubber nub matt over a smooth acrylic sheet to 
hide the rod floors, no curtain, a blue sheet covering the clear acrylic backs, and blue lights (4 lux); floor pans and rods were cleaned using a vanilla scent and floor pans received 4 sprays of the vanilla scent to provide a distinct background odor. 7 days after E3, mice were tested for long-term fear recall in Context A or B.

\section{Open field test}

To assess differences in locomotor activity levels between strains open field experiments were conducted as described previously (Krueger et al. 2017; Perkowski \& Murphy 2011). Briefly, these were carried out in a $53 \times 38 \times 26 \mathrm{~cm}$ open box with smooth white opaque acrylic walls and floor (Chemtainer; Lombard, IL). Illumination in the center of the box was $\sim 38$ lux. Animals were released in the center of the box and allowed to freely explore for 10 minutes. Actimetrics Limelight version 4 software (Wilmette, IL), run on a desktop PC using individual cameras mounted above each open field box, was used to record behavior and calculate total distance traveled and time spent in the center and perimeter.

\section{Statistical analyses}

Minimum sample sizes were pre-determined using response means and variance obtained from a series of pilot experiments (sample size of 10 per group resulted in $60 \%$ power for detecting a moderate effect (Cohen's $d=0.65)$ at $\alpha=0.5$, (Cohen 1988)). Sample sizes for individual experiments are reported in the figure legends. To avoid skewing the data with any potential sex differences, a balanced designed was used in each experiment with approximately equal number of males and females. Fear conditioning and extinction training videos were quantified 
using Freeze Frame 4 software, with automated detection of freezing, which was defined as 1 second bouts of nearly complete animal immobility except for the movement necessary for breathing. Percent time freezing was calculated as the time spent freezing divided by the total session time. In a subset of experiments, human observers verified the automated detection of freezing by manually scoring videos; a representative comparison between automated and human scoring in shown in supplementary Figure 1 (Figure S1, A and B). Data was exported in comma-separated variable format from Freeze Frame 4, averaged across the duration of either pre-tone, CS by type (and binned into groups of 3 CS of the same kind), footshock (when applicable), and post-tone periods. To assess discriminative freezing between the CS+ and CS, a discrimination ratio was calculated as freezing to CS+ divided by the sum of freezing to CS+ and CS-. Subsequent statistical data analyses and plotting was done in R Studio (Team 2016) using open-source packages (e.g. (Singmann et al. 2015; Wickham 2010; Nuñez et al. 2018; Wickham et al. 2015)) and custom-written scripts. Statistical analyses employed were multifactor analysis of variance (ANOVA) for parametric data including between and/or within subjects factors. Specifically, for the analysis of within-session extinction (panel C of each figure), the data were analyzed separately by strain and collapsed across days since our results show significant trial-to-trial variability and within-session locomotor differences (see US- groups in all figures). Between-session extinction was analyzed using a 2-factor (training day, strain), between-subjects ANOVA with freezing data averaged across bins for each training day. For further interrogation of statistically significant ANOVA effects, post-hoc Tukey's t-tests for multiple comparisons were carried out as indicated in text

This article is protected by copyright. All rights reserved. 


\section{Results}

\section{Fear conditioning and extinction phenotypes for C57BL/6 \& $129 S 1$ mice}

We first sought to establish phenotypes for discriminative fear conditioning and extinction learning for $129 S 1$ and C57BL/6 mice using validated behavioral protocols (Herry et al. 2010; Grewe et al. 2017). A statistical analysis of fear conditioning data yielded a main effect of training (i.e. CS+ presentations) for freezing $\left(F_{(3,105)}=43.15 ; p<0.001\right)$ with no strain interaction, suggesting that there were no difference between $129 \mathrm{~S} 1$ and C57BL/6 mice in associative fear learning (Figure 1A). Similarly, both strains were equally able to discriminate between CS type $\left(C S+/ \mathrm{CS}^{-}\right)$as evidenced by a main effect of $\mathrm{CS}$ type on freezing $\left(F_{(1,70)}=\right.$ 48.79; $p<0.001$ ) with no strain interaction or differences in the mean discrimination ratio (defined as freezing to CS+ divided by the sum of freezing to CS+ and CS-). All together, these findings indicate that both $129 \mathrm{~S} 1$ and C57BL/6 displayed effective associative learning and could discriminate $\mathrm{CS}+$ from $\mathrm{CS}^{-}\left(\right.$Figures $\left.1 \mathrm{~B}_{1}-\mathrm{B}_{2}\right)$. The US- groups were analyzed separately and showed no significant increase in freezing in response to tone presentations and no differences between strains.

To assess the ability of each strain to reduce freezing behavior when the CS+ was not paired with a footshock, we measured within-session extinction learning (Figure 1C). Withinsession extinction was statistically assessed using separate one-way repeated measures ANOVA per strain. Our results show that C57BL/6 mice exhibit a statistically significant decrease in freezing as a factor of CS+ presentations $\left(F_{(8,132)}=4.98 ; p<0.001\right)$, while $129 S 1$ mice did not. In agreement with prior studies, these data demonstrate the presence of extinction learning deficits in the $129 \mathrm{~S} 1$ strain as compared to C57BL/6 mice (Hefner et al. 2008; Camp et 
al. 2009; Temme et al. 2014). Analysis of discrimination performance during extinction (Figure $\left.1 D_{1}\right)$ shows a main effect of CS type $\left(C S+/ C S^{-}, F_{(1,202)}=82.5 ; p=0.001\right)$ and a main effect of strain $\left(F_{(1,202)}=24.34 ; p=0.001\right)$ on freezing. Furthermore, no statistically significant differences were found in the mean discrimination ratio (Figure $1 \mathrm{D}_{2}$ ), supporting the conclusion that both strains of mice were capable of discriminating the CS type, though 129S1 mice freeze more significantly to both $\mathrm{CS}+$ and $\mathrm{CS}^{-}$(main effect of strain, $F_{(1,202)}=24.34 ; \mathrm{p}<0.001$ ).

To monitor the consolidation and recall of extinction memories, freezing between extinction training sessions was measured. For this analysis, freezing levels were averaged across all CS+ presentations for each extinction training session (Figure 1E). Our analyses revealed a main effect of mouse strain $\left(F_{(1,60)}=9.97 ; p<0.01\right)$, but no effect of training session which indicates that while C57BL/6 mice freeze less than 129S1, neither strain's freezing levels significantly decreased between extinction training sessions. In contrast to these results, previous studies (and Figure S2, A-B) demonstrate that C57BL/6 mice exhibit greater levels of within-session extinction and efficient consolidation of extinction memories over days (Hefner et al. 2008; Camp et al. 2009; Temme et al. 2014); this discrepancy in results may be explained by the fact that these studies used greater number of unreinforced CS+ presentations (20-30 vs. 12 per extinction training session in the current study).

Interestingly, the US- groups (Figure 1C, dashed lines) showed a within-session increase in what is scored as "freezing" $\left(F_{(10,140)}=3.29 ; p<0.001\right)$, but since there is no paired aversive stimulus, this phenotype must be interpreted as an indiscriminate fear response or a lack of motivated locomotion. This phenotype is particularly pronounced in the 12951 mouse strain, which "froze" significantly more than the C57BL/6 $\left(F_{(1,14)}=34.91 ; p=0.0001\right)$. To verify 
that automated tracking of freezing behavior was accurately assessing bouts of freezing, a subset of behavioral videos was manually scored by experimenters, and similar results were found (Figure S1 A and B). To further corroborate this phenotype, we employed an open-field test to measure overall locomotor activity. Our results (Figure S3, C-D) revealed that 129 S1 mice show significantly reduced levels of overall locomotion $(C 57 B L / 6=10.13$ meters, \pm 0.44 vs. $129 S 1=4.27$ meters, $\left.\pm 0.38 ; t_{(14)}=5.21, p<0.0001\right)$ and spend less time in the center of the field $\left(\mathrm{C} 57 \mathrm{BL} / 6=39.06 \%, \pm 2.25\right.$ vs. $\left.129 \mathrm{~S} 1=18.19 \%, \pm 2.98 ; t_{(14)}=1.12, \mathrm{p}<0.01\right)$. Consistent with many prior studies, these results suggest that untrained or experimentally naïve 129 S1 mice display greater levels of baseline anxiety-like behavior and/or decreased levels of locomotion (Crawley et al. 1997; Võikar et al. 2001; Dockstader \& van der Kooy 2001). In addition, our results show an increase in between-session freezing (Figure 1F, main effect of strain, $\left.F_{(1,42)}=38.19 ; p<0.001\right)$, whereby the 129 S1 strain showed a greater level of "freezing". This increased immobility was consistent across all extinction training days, with no effects of training session (Figure 1F).

Pipped tones enhance fear discrimination and within-session extinction in both C57B6 \& 12951 mice

In vivo neurophysiological recordings in the medial prefrontal cortex, amygdala, and other brain regions most commonly utilize pipped tones rather than continuous tones due to the fact that they yield greater neural activity (Quirk et al. 1997; Herry et al. 2010; Blair et al. 2005). Tone pips have also been found to enhance stimulus discrimination during fear conditioning (Bang et al. 2008; Ito et al. 2009). Recently, high-frequency tone pips $(40 \mathrm{~Hz})$ were also found to entrain gammafrequency firing patterns in mPFC, auditory cortex and hippocampus—this treatment led to 
enhancements spatial memory in mice (Martorell et al. 2019). Based on these observations, we tested the effectiveness of pipped tones for training $129 \mathrm{~S} 1$ and C57BL/6 mice on discriminative fear conditioning and extinction learning. Similar to the results from the continuous tone experiment, using pipped tones results in a significant effect of training (i.e. CS+ presentations) on freezing $\left(F_{(3,87)}=22.76 ; \mathrm{p}<0.001\right)$ with no strain interaction, suggesting that both $129 \mathrm{~S} 1$ and C57BL/6 form an association between the CS+ and footshock to a similar degree (Figure 2A). Furthermore, there was a main effect of CS type (ie, $\left.\mathrm{CS}+/ \mathrm{CS}^{-}\right)$on freezing $\left(F_{(1,58)}=76.51 ; \mathrm{p}<\right.$ 0.001) indicating that both strains could discriminate CS+ from $\mathrm{CS}^{-}$. Importantly, there was also a significant strain $x$ CS type interaction (Figure $2 \mathrm{~B}_{1}, F_{(1,58)}=7.81 ; p<0.01$ ), suggesting that C57BL/6 discriminate between CS+ and CS- tones to a higher degree. In agreement with this analysis, the discrimination ratio was significantly higher for C57BL/6 mice compared to $129 \mathrm{~S} 1$ mice (Figure $\left.2 \mathrm{~B}_{2}, t_{(29)}=3.977, \mathrm{p}<0.001\right)$. Additionally, a comparison of the discrimination ratios for the continuous tone protocol (Figures $1 \mathrm{~B}_{1}-\mathrm{B}_{2}$, means $=0.66,0.64$ for $129 \mathrm{~S} 1$ and $\mathrm{C} 57 \mathrm{BL} / 6$, respectively) and the pipped tone protocol (Figures $2 \mathrm{~B}_{1}-\mathrm{B}_{2}$, means $=0.82,0.97$ for $129 \mathrm{~S} 1$ and C57BL/6, respectively) suggest that pipped tones enhance discrimination learning for both strains. As was the case using the continuous tone protocol, neither the $129 \mathrm{~S} 1$ nor the C57BL/6 US- groups showed an increase in freezing over time or with tone presentation alone.

In contrast to the continuous tone experiments, the pipped tone protocol led to significant within-session extinction learning for both C57BL/6 mice $\left(F_{(11,77)}=3.31 ; p<0.001\right)$ and $129 \mathrm{~S} 1$ mice $\left(F_{(11,77)}=1.98 ; \mathrm{p}<0.05\right)$ (Figure $\left.2 \mathrm{C}\right)$. Similarly, as in fear conditioning, both $129 \mathrm{~S} 1$ and C57BL/6 mice were able discriminate between the CS+ and CS during extinction training (Figure $2 \mathrm{D}_{1}$, main effect of CS type, $F_{(1,58)}=76.51 ; p<0.001$ ). Further, analysis of the 
discrimination ratio revealed that C57BL/6 mice discriminate the CS+ better than $129 \mathrm{~S} 1$ mice $\left(\right.$ Figure $2 \mathrm{D}_{2}, 129 \mathrm{~S} 1$ mean $=0.71 \pm 0.02, \mathrm{C} 57 \mathrm{BL} / 6$ mean $\left.=0.90 \pm 0.03, t_{(29)}=5.17, \mathrm{p}<0.0001\right)$. However, analysis of freezing levels between-session (Figure 2E), resulted in no significant effects, suggesting that using pipped CS tones did not impact the consolidation or recall of extinction memories.

Again, statistical analysis of the US- groups revealed a main effect of strain $\left(F_{(1,42)}=\right.$ 71.09; $p<0.0001$ ), indicating that the 129S1 mice displayed significantly higher "freezing" (even though they never received a footshock) than the C57BL/6 mice. Further, there was also a main effect of 'training session' $\left(F_{(2,42)}=3.4 ; p<0.05\right)$, indicating that there was an increase in 'freezing' over training days (Figure 2F).

\section{Delayed extinction training does not impact the performance of $129 \mathrm{~S} 1$ or C57BL/6 mice}

To examine the possibility that heightened fear from the fear conditioning context or fear generalization might suppress extinction learning and consolidation, we imposed a 7-day delay between fear conditioning and extinction learning. As expected, analysis of fear conditioning results demonstrated that both $129 \mathrm{~S} 1$ and C57BL/6 mice learned the association between the $\mathrm{CS}+$ and the footshock as revealed by a main effect of training (i.e. CS+ presentations) on freezing $\left(F_{(3,42)}=11.9 ; p<0.001 ;\right.$ Figure $\left.3 \mathrm{~A}\right)$. In addition, both strains were able to discriminate between CS+ and CS- tones (main effect of tone on freezing, $F_{(1,26)}=63.62 ; p<0.0001$, Figure $3 \mathrm{~B}_{1}$ ). In agreement with previous experiments (Figure 2), analysis of the discrimination index indicates that C57BL/6 exhibit better discrimination when compared to the $129 \mathrm{~S} 1$ mice (Figure $3 \mathrm{~B}_{2}, 129 \mathrm{~S} 1$ mean $=0.73 \pm 0.04, \mathrm{C} 57 \mathrm{BL} / 6$ mean $\left.=0.89 \pm 0.04, t_{(14)}=2.9955, \mathrm{p}<0.01\right)$. The US- 
groups were analyzed separately and showed no significant increase in freezing over time or with tone presentations alone, and demonstrated no differences between strains.

Similar to experiments in which extinction training was performed immediately after fear conditioning, when extinction training was delayed by 7 days both strains of mice exhibited significant within-session extinction learning (Figure 3C, C57BL/6 mice: main effect of training $\left(F_{(11,132)}=2.68 ; p<0.01\right.$ and $129 S 1$ mice: main effect of training, $\left.F_{(11,132)}=3.15 ; p<0.001\right)$. Likewise, both strains were able to discriminate between the CS+ and CS- tones (main effect of tone type, $\left.F_{(1,48)}=40.96 ; \mathrm{p}<0.0001\right)$ although $\mathrm{C} 57 \mathrm{BL} / 6$ mice had enhanced discrimination relative to the $129 \mathrm{~S} 1$ mice $\left(129 \mathrm{~S} 1\right.$ mean $=0.67 \pm 0.02, \mathrm{C} 57 \mathrm{BL} / 6$ mean $=0.87 \pm 0.02, t_{(62)}=5.90$, $p<0.0001$; Figure $3 D_{2}$ ). Neither $129 S 1$ nor C57BL/6 showed a between-session reduction in freezing (Figure 3E).

The 7-day delay protocol also did not change the increase in immobility observed in the $129 S 1$ group within-session (Figure $2 \mathrm{C}$, main effect of strain, $F_{(1,42)}=33.29 ; \mathrm{p}<0.0001$ ) or between-session (Figure 2F, main effect of strain, $F_{(1,28)}=48.07$; $p<0.0001$; main effect of session, $\left.F_{(3,21)}=3.91 ; \mathrm{p}<0.05\right)$.

\section{Exposure to novel contexts during training enhances the consolidation of extinction learning across training sessions}

Our experiments modulating the parameters of a discrete CS led us to hypothesize that altering the context might also stimulate the consolidation of extinction learning. As in our previous experiments, both $129 S 1$ and C57BL/6 mice displayed normal fear conditioning (main effect of training, $\left.F_{(3,39)}=10.735 ; \mathrm{p}<0.001\right)$ with no differences between the strains (Figure 4A). Again, 
both strains were able to discriminate between CS+ and CS- (main effect of CS type, $F_{(1,26)}=$ 78.04; $p<0.0001$ ) with C57BL/6 mice displaying better discrimination as evidenced by a significant interaction between $\mathrm{CS}$ type and strain (Figure $4 \mathrm{~B}_{1}{ }^{\prime} F_{(1,26)}=8.61 ; p<0.01$ ) during conditioning along with a higher discrimination ratio (Figure $4 \mathrm{~B}_{2}, 129 \mathrm{~S} 1$ mean $=0.67 \pm 0.02$, C57BL/6 mean $\left.=0.86 \pm 0.03, t_{(13)}=4.9561, p<0.001\right)$. As before, the US- groups were analyzed separately and showed no significant increase in freezing over time with presentations of tone alone and there were no differences between strains.

Using daily novel contexts for extinction training resulted in effective within-session extinction learning with both C57BL/6 mice $\left(F_{(11,46)}=9.49 ; \mathrm{p}<0.001\right)$ and $129 \mathrm{~S} 1$ mice $\left(F_{(11,80)}=\right.$ 13.11; $p<0.001$ ) displaying significant decreases in freezing. We also found main effects for CS type $\left(F_{(1,34)}=92.98 ; p<0.0001\right)$ indicating that both strains could discriminate CS+. However, our results indicate that the $129 \mathrm{~S} 1$ still exhibit higher freezing levels (Figure $4 \mathrm{D}_{1}$, main effect of strain $\left.\left(F_{(1,34)}=93.44 ; p<0.0001\right)\right)$. Analysis of the discrimination ratio confirmed that C57BL/6 mice discriminate the $C S+$ better than $129 S 1$ mice (Figure $4 D_{2}, 129 S 1$ mean $=0.66 \pm$ $0.02, \mathrm{C} 57 \mathrm{BL} / 6$ mean $\left.=0.93 \pm 0.02, t_{(17)}=12.68, \mathrm{p}<0.0001\right)$.

Importantly, exposing mice to a new context for each extinction training day significantly enhanced consolidation and recall of tone extinction memories between sessions (Figure 4E; main effect of training session $\left.F_{(2,111)}=20.9 ; p<0.0001\right)$. Post-hoc analysis revealed that both strains significantly reduced their level of freezing to the CS+ between extinction Day 1 and Day 2 (Figure 4E, $129 \mathrm{~S} 1 \Delta=21.28 \pm 5.67, t_{(146)}=3.75, \mathrm{p}<0.01 ; \mathrm{C} 57 \mathrm{BL} / 6 \Delta=23.89 \pm 6.45, t_{(146)}=3.7$, $p<0.01)$. Interestingly, while both strains showed significant decreases in freezing over the 
course of extinction training, C57BL/6 mice froze significantly less than 129S1 during each session (main effect of mouse strain $\left(F_{(1,111)}=53.41 ; p<0.0001\right)$.

Reductions in between-session freezing suggest that repeated extinction training in novel contexts enhances consolidation and/or recall of learning. To test if extinction learning was maintained long-term, we compared freezing levels from extinction Day 3 to performance during a recall test 7 days later (7-day tone test). We found no significant differences indicating that both strains exhibit long-term extinction memory. Furthermore, we tested if extinction training in novel contexts would effectively extinguish fear responses even in the conditioning context. We found no differences in freezing levels between extinction day 3 (Context D) and the 7-day tone test in the conditioning context $(A)$, indicating robust and specific extinction of the tone-footshock association.

Once again, the US- groups showed elevated immobility, particularly in the 129S1 mouse strain, which showed significantly more "freezing" than the C57BL/6 $\left(F_{(1,32)}=26.64 ; p=\right.$ 0.0001), and there was no effect of CS+ presentation (Figure 4C, dashed lines) or training session (Figure 4F).

\section{Discussion}

In this study, we report on the important role that environmental characteristics play in the capability of wild-type mice from two inbred mouse strains to discriminate between stimuli that are predictive of aversive outcomes (vs. neutral outcomes) and to enhance learning and consolidation of extinction memory. Specifically, this study shows that utilizing pipped rather than continuous tones during extinction training ameliorates learning deficits in 129S1 mice and

This article is protected by copyright. All rights reserved. 
that repeated extinction training is more effective when conducted in multiple contexts than a single repeated context.

In agreement with prior studies, we found that 12951 mice fear condition to tone stimuli as well as C57BL/6 mice (Hefner et al. 2008; Camp et al. 2009; Temme et al. 2014). Our results also replicate the observation that $129 S 1$ mice have conditioned fear extinction deficits when a continuous tone is used as a CS (Hefner et al. 2008; Camp et al. 2009; Temme et al. 2014). Critically, we found that altering the CS from a continuous to a discontinuous tone ('pip') significantly enhanced discrimination learning for both strains and ameliorated the withinsession extinction learning deficits in the $129 S 1$ mice. The use of tone pips as CS is not without precedent, as pipped tones have been used extensively in neurophysiological studies of fear learning and extinction (Quirk et al. 1997; Herry et al. 2010; Blair et al. 2005) and more recently to enhance spatial memory in mice (Martorell et al. 2019). Pipped tones more closely mimic the auditory features of ultrasonic vocalizations of rodents and recruit the same brain structures during fear conditioning (Furtak et al. 2007; Bang \& Brown 2009). The effects of pipped tones as a CS on extinction learning have not been systematically studied, but our findings are corroborated by (Camp et al. 2012), in which the effect of pips was not explicitly tested, but were shown to improve within-session extinction learning in 12951 when compared to studies that used continuous tones (Hefner et al. 2008; Camp et al. 2009; Whittle et al. 2010; Temme et al. 2014). We further show that while pips improved within-session extinction, they did not impact the consolidation of extinction learning in the $129 \mathrm{~S} 1$ or C57BL/6 strains.

Further studies are needed to elucidate the neurophysiological mechanisms of how pips improve fear discrimination and extinction learning. It is possible that pips more reliably recruit 
the relevant neural circuits for extinction learning than do continuous tones. Likely neurophysiological targets would include: neurons in the medial prefrontal cortex and in the basal amygdala that have been shown to become active and phase locked to CS presentations in extinction training (Milad \& Quirk 2002; Herry et al. 2010; Grewe et al. 2017); activation of the GABA-releasing intercalated cells (ITCs, (Amano et al. 2010; Likhtik et al. 2008; Chhatwal et al. 2005; H.-C. Lin et al. 2009)); or NMDA receptor-dependent activity in the BLA (Laurent \& Westbrook 2008; Laurent:2008ed Laurent \& Westbrook 2010). Interestingly, recent studies suggest that recruitment of ITCs and/or NMDARs are mechanisms engaged primarily during the initial extinction session but are less engaged during subsequent training in the same environment (Laurent \& Westbrook 2008; Laurent et al. 2008; An et al. 2017). Consistent with this idea, our results showed that the utilization of pips positively influenced within-session extinction but had little to no effect on the consolidation and performance on subsequent training days. From a behavioral theory perspective, it is possible that the effects of pips may be explained by the difference in predictive value between a single continuous tone vs numerous pips. However, it is unlikely that the effectiveness of pips can be fully explained as 'mass extinction training' as the mass extinction method has been shown to be ineffective for $129 \mathrm{~S} 1$ mice (MacPherson et al. 2013; Whittle et al. 2013).

To further our studies on environmental variables that facilitate extinction learning and consolidation, we tested the possibility that delaying extinction training relative to fear conditioning would enhance extinction learning. Our hypothesis was that extinction training would be more effective with greater separation from the aversive experience. Overall, imposing a 7-day delay after fear conditioning did not appear to alter the extinction or discrimination 
learning phenotype relative to training on consecutive days (Figure 2). These results are consistent with rodent and human studies that suggest that remote traumatic memories are more resistant to extinction or exposure therapy. (Tsai \& Gräff 2014; Pitman \& Delahanty 2005). In light of our results suggesting that changing the quality of the CS was effective in modulating maladaptive fear, we tested the possibility that extinction training within a daily novel context might enhance consolidation of extinction memories. Using the novel context paradigm, we found significant enhancements in the consolidation and recall of extinction learning. More specifically, our results demonstrate that using daily novel context reduced freezing levels in the C57BL/6 to levels near those seen prior to fear conditioning, while the $129 \mathrm{~S} 1$ performance is improved and more closely resembles C57BL/6 performance. Remarkably, we find that extinction recall is maintained for both strains even when the extinguished CS+ is presented in the original fear conditioning context (Figure 4, 7-day tone test, Context A). This data suggests that the enhancement in the consolidation of extinction learning is proportional to the number of new contexts experienced. Given that extinction performance is believed to rely on the formation of new memories, extinction may be enhanced because a greater number of associations (memories) between the CS and non-aversive environments are formed. In support of this idea, a recent study in human finds that replacing threat stimuli with neutral stimuli facilitates extinction learning by engaging ventromedial PFC (Dunsmoor et al. 2019).From a neurophysiological perspective, one hypothesis to be tested is that using a daily novel context may retain the engagement of neural circuits underlying extinction learning that usually attenuate after the first day of training in the same context (Laurent \& Westbrook 2008; Laurent \& Westbrook 2010; An et al. 2017). These results may also have important implications 
for the effectiveness of cognitive-behavioral therapies based on extinction learning, such as those used to treat PTSD. It may be valuable in human subjects to increase the number of therapeutic contexts in which an unreinforced CS+ is presented and determine whether this reduces physiological fear responses as well as self-reported fear.

Finally, our experiments show that untrained $129 S 1$ exhibit significantly decreased levels of locomotion and exploratory behavior over time compared to C57BL/6. These results are in support of previous studies showing that the 12951 have reduced levels of locomotion and increased basal maladaptive fear behavior (Crawley et al. 1997; Võikar et al. 2001; Dockstader \& van der Kooy 2001). This observation is very important for fear learning and memory studies in $129 \mathrm{~S} 1$ mice as it can impact the interpretation of experiments in which the lack of movement (i.e. freezing) is the primary dependent variable. Our studies are unable to fully distinguish whether increased immobility in the $129 \mathrm{~S} 1$ is due to, or influenced by, innate fear to the experimental contexts or is a phenotype that is independent of fear or anxiety. The high level of immobility was not observed during initial training (see pre-tone, panel A of each figure) and increased over time, which suggests reduced attention or a lack of motivation for exploration versus a fear phenotype. In fact, 12951 have previously been shown to have drastically lower exploratory behavior even in home cage-like environments (Loos et al. 2014). Thus, the increased immobility phenotype of the naïve $129 S 1$ suggests that some degree of extinction learning may be masked. Given the abundance of behavioral and neurophysiological data, the existence of extinction learning deficits in the 12951 seem incontrovertible, which is further consistent with the data presented herein, but researchers should take note that US- controls are likely needed for full interpretation of behavioral data. The attenuated motivation for 
approach and exploratory behavior in the $129 S 1$ may also be indicative of other neural circuitry deficits underlying motivation, and as such, may represent key factors that contribute to the extinction learning deficits in the 129S1. Elucidating the contributions of each of these phenotypes and the underlying neuronal circuitry is of utmost importance because the balance between approach and escape behavior is a critical component to extinction learning, which has translatable implications for the diagnosis and treatment of PTSD in humans (Fenster et al. 2018).

This article is protected by copyright. All rights reserved. 


\section{Figure 1:}

\section{Comparisons between $129 \mathrm{~S} 1$ and C57BL/6 on discriminative fear conditioning and}

extinction learning. (A) Analysis of training data. Two separate groups of mice were used in this experiment. Mice in the US+ group (solid lines, C57BL/6; $n=20$ [11 males; 9 females], 129S1; $n=17$ [8 males; 9 females],) were exposed to auditory stimuli which consisted of white noise (CS-; white noise, 25 seconds) or $4 \mathrm{kHz}$ pure tone (25 seconds) which co-terminated with a foot shock (CS+). Mice in the US- group (dashed lines, C57BL/6 $n=8,129 S 1 n=8$ ) received the identical auditory stimuli but did not receive the foot shocks. Mice in the US+ group exhibited increased freezing across the training session (repeated measures ANOVA; effect of training, $p$ $<0.001$ ) independent of strain. In the absence of shock, mice in the US- group did not exhibit significant levels of freezing. (B) Analysis of discrimination learning during training. The mean percent freezing averaged across all CS+ presentations during training was significantly greater in both strains when compared with the mean freezing in response to the CS- presentations $\left(B_{1}\right.$, 2-factor ANOVA; effect of CS, $p<0.001$ ) and there was no difference in the discrimination ratios for the two strains $\left(B_{2}\right)$. (C) Analysis of within session extinction learning. Twenty-four hours following training, mice in both groups where exposed to four CS- stimuli followed by twelve CS+ presentations (displayed in bins of 4 stimuli) in a new context (Context B) for three days (Extinction Day 1-3). Repeated exposure of the C57BL/6 mice to the CS+ tone in the US+ group resulted in significantly less freezing within extinction sessions shown by a repeated measures ANOVA, where data is collapsed across days of training; (effect of bin, $p<0.001$ ). Conversely, repeated exposure to the CS+ tone in the absence of shock in the 12951 mice failed to reduce freezing within the extinction sessions. (D) Analysis of tone discrimination during extinction. 
Mice in both strains exhibited significantly more freezing when exposed to the CS+ tone (2factor ANOVA; effect of CS, $p<0.001$ ) and significant differences in freezing by strain (effect of Strain, $p<0001)\left(D_{1}\right)$. Similarly, there was no significant difference between the C57BL/6 and $129 S 1$ strains when the discrimination ratio was calculated $\left(D_{2}\right)$. $(E)$ Analysis of extinction across days (US+ Group). Freezing across extinction days was analyzed by calculating the mean percent freezing for the three binned CS+ presentations for each of the three extinction days (solid line in panel C). While both C57BL/6 and 12951 mice exhibited modest reductions in freezing across extinction days, this effect was not significant, although 12951 mice freeze more as compared to the C57BL/6 (2-factor ANOVA; effect of strain, $p<0.001)$. (F) Analysis of freezing in the US- group across days. Freezing in the US- group was calculated each day as the mean percent freezing measured during the CS+ tone presentations (dashed line in panel C). Somewhat surprisingly, the 12951 mice exhibited increased 'freezing' across the three days of re-exposure to the CS+ tone compared with the B6 strain (2-factor ANOVA; effect of strain, $p$ $<0.0001)$, in spite of the fact that they never received the foot shock. Data shown as sample mean with shaded region or bars representing the standard error of the mean. Asterisk $\left(^{*}\right)$ denotes statistical significance for main effect of training (horizontal line) or strain (vertical line). Data are presented as mean \pm SEM.

This article is protected by copyright. All rights reserved. 


\section{Figure 2:}

\section{Pipped tone CS presentations ameliorate extinction deficits in 1295 mice and enhance}

discrimination learning for both C57BL/6 and 129S mice. (A) Analysis of training data. Two separate groups of mice were used in this experiment. Mice in the US+ group (solid lines, C57BL/6 $n=13$ [7 males; 6 females], 129S1 $n=18$ [10 males; 8 females]) were exposed to discontinuous or pipped auditory stimuli which consisted of white noise (CS-; 200 ms white noise pips, delivered at $1 \mathrm{~Hz}$ for 25 seconds) or $4 \mathrm{kHz}$ pure tone (200 ms pips, delivered at $1 \mathrm{~Hz}$ for 25 seconds) which co-terminated with a foot shock (CS+). Mice in the US-group (dashed lines, C57BL/6 $n=8,129 S 1 n=8$ ) received the identical auditory stimuli but did not receive the foot shocks. Mice in the US+ group exhibited increased freezing across the training session (repeated measures ANOVA; effect of training, $p<0.001$ ) independent of strain. In the absence of shock, mice in the US- group did not exhibit significant levels of freezing. (B) Analysis of discrimination learning during training. The mean percent freezing averaged across all CS+ presentations during training was significantly greater in both strains when compared with the mean freezing in response to the CS- presentations $\left(B_{1}, 2\right.$-factor ANOVA; effect of $C S, p<$ 0.001). However, calculation of the discrimination ratio revealed that C57BL/6 discriminate CS+ from CS- better than $129 S 1$ mice $\left(B_{2}\right.$, unpaired t-test, $\left.p<0.001\right)$. (C) Analysis of within session extinction learning. Twenty-four hours following training, mice in both groups where exposed to four CS- stimuli followed by twelve CS+ presentations (displayed in bins of 4 stimuli) in a new context (Context B) for three days (Extinction Day 1-3). Repeated exposure to the CS+ tone in the US+ group resulted in significantly less freezing within extinction sessions for both strains (using separate repeated measures ANOVA per strain; effect of bin, $p<0.05$ ). (D) Analysis of 
tone discrimination during extinction. Mice in both strains exhibited significantly more freezing when exposed to the CS+ tone (repeated measures ANOVA; effect of training, $D_{1}, p<0.001$ ). However, the C57BL/6 showed significantly better freezing discrimination to the CS+ (unpaired t-test, $p<0.0001)$ than $129 S 1$ strain when the discrimination ratio was calculated $\left(D_{2}\right) .(E)$ Analysis of extinction across days (US+ Group). Freezing across extinction days was analyzed by calculating the mean percent freezing for the three binned CS+ presentations for each of the three extinction days (solid line in panel C). No statistically significant reductions in freezing were observed for either C57BL/6 and 129S1 mice. (F) Analysis of freezing in the US- group across days. Freezing in the US- group was calculated each day as the mean percent freezing measured during the CS+ tone presentations (dashed line in panel C). The $129 \mathrm{~S} 1$ mice exhibited increased 'freezing' across the three days of re-exposure to the CS+ tone compared with the B6 strain (repeated measures ANOVA; effect of "extinction" day, $p<0.0001$ ), in spite of the fact that they never received the foot shock. Data shown as sample mean with shaded region or bars representing the standard error of the mean. Asterisk $\left(^{*}\right)$ denotes statistical significance for main effect of training (horizontal line) or strain (vertical line) and a dagger ( $†$ ) for significant interaction between main effects. Data are presented as mean \pm SEM. 


\section{Figure 3:}

\section{Delaying extinction training by 7 days does not impact extinction learning or}

discrimination of the CS+. (A) Analysis of training data. Two separate groups of mice were used in this experiment. Mice in the US+ group (solid lines, C57BL/6 $n=8$ [4 males; 4 females], 129S1 $n=8$ [4 males; 4 females]) were exposed to discontinuous or pipped auditory stimuli which consisted of white noise (CS-; 200 ms white noise pips, delivered at $1 \mathrm{~Hz}$ for 25 seconds) or $4 \mathrm{kHz}$ pure tone (200 ms pips, delivered at $1 \mathrm{~Hz}$ for 25 seconds) which co-terminated with a foot shock (CS+). Mice in the US- group (dashed lines, C57BL/6 $n=8,129 S 1 n=8$ ) received the identical auditory stimuli but did not receive the foot shocks. Mice in the US+ group exhibited increased freezing across the training session (repeated measures ANOVA; effect of training, $p$ $<0.001$ ) independent of strain. In the absence of shock, mice in the US- group did not exhibit significant levels of freezing. (B) Analysis of discrimination learning during training. The mean percent freezing averaged across all CS+ presentations during training was significantly greater in both strains when compared with the mean freezing in response to the CS- presentations $\left(B_{1}\right.$, 2-factor ANOVA; effect of CS, $p<0.0001)$. However, calculation of the discrimination ratio revealed that $\mathrm{C} 57 \mathrm{BL} / 6$ discriminate the $\mathrm{CS}+$ and $\mathrm{CS}$ - better than $129 \mathrm{~S} 1$ mice $\left(\mathrm{B}_{2}\right.$, unpaired $\mathrm{t}$ test, $p<0.01$ ). (C) Analysis of within session extinction learning. Seven days following training, mice in both groups where exposed to four CS- stimuli followed by twelve CS+ presentations (displayed in bins of 4 stimuli) in a new context (Context B) for three days (Extinction Day 1-3). Repeated exposure to the CS+ tone in the US+ group resulted in significant decreases in freezing within extinction sessions for both strains (using separate repeated measures ANOVA per strain; effect of bin, $p<0.01$ ). (D) Analysis of tone discrimination during extinction. Mice in 
both strains exhibited significantly more freezing when exposed to the $C S+$ tone $\left(D_{1}, 2\right.$-factor ANOVA; effect of CS, $p<0.001)$. However, the C57BL/6 showed significantly better freezing discrimination to the CS+ compared with the $129 \mathrm{~S} 1$ strain when the discrimination ratio was calculated $\left(D_{2}\right.$, unpaired t-test; $\left.p<0.0001\right)$. (E) Analysis of extinction across days (US+Group). Freezing across extinction days was analyzed by calculating the mean percent freezing for the three binned CS+ presentations for each of the three extinction days (solid line in panel C). No statistically significant reductions in freezing were observed for either C57BL/6 and 129S1 mice. (F) Analysis of freezing in the US- group across days. Freezing in the US- group was calculated each day as the mean percent freezing measured during the CS+ tone presentations (dashed line in panel C). The 12951 mice exhibited increased 'freezing' across the three days of reexposure to the CS+ tone compared with the C57BL/6 strain (2-factor ANOVA; effect of strain, $p<0.0001)$, in spite of the fact that they never received the foot shock. Data shown as sample mean with shaded region or bars representing the standard error of the mean. Asterisk $\left({ }^{*}\right)$ denotes statistical significance for main effect of training (horizontal line) or strain (vertical line) and a dagger $(\dagger)$ for significant interaction between main effects. Data are presented as mean \pm SEM

This article is protected by copyright. All rights reserved. 


\section{Figure 4:}

\section{Presentation of unpaired CS+ tones in novel contexts during extinction training}

enhances the consolidation of extinction learning across training sessions. (A) Analysis of training data. Two separate groups of mice were used in this experiment. Mice in the US+ group (solid lines, C57BL/6 $n=17$ [10 males; 7 females], 129S1 $n=22$ [11 males; 11 females]) were exposed to discontinuous or pipped auditory stimuli which consisted of white noise (CS-; $200 \mathrm{~ms}$ white noise pips, delivered at $1 \mathrm{~Hz}$ for 25 seconds) or $4 \mathrm{kHz}$ pure tone (200 ms pips, delivered at $1 \mathrm{~Hz}$ for 25 seconds) which co-terminated with a foot shock (CS+). Mice in the USgroup (dashed lines, C57BL/6 $n=8,129 S 1 n=8$ ) received the identical auditory stimuli but did not receive the foot shocks. Mice in the US+ group exhibited increased freezing across the training session (repeated measures ANOVA; effect of training, $p<0.001$ ) independent of strain. In the absence of shock, mice in the US- group did not exhibit significant levels of freezing. (B) Analysis of discrimination learning during training. The mean percent freezing averaged across all CS+ presentations during training was significantly greater in both strains when compared with the mean freezing in response to the CS- presentations $\left(B_{1}, 2\right.$-factor ANOVA; effect of CS, $p<0.001)$. However, calculation of the discrimination ratio revealed that C57BL/6 discriminate CS+ and CS- better than $129 S 1$ mice $\left(B_{2}\right.$, unpaired t-test, $\left.p<0.001\right) .(C)$ Analysis of within session extinction learning. Twenty-four hours following training, mice in both groups where exposed to four CS- stimuli followed by twelve CS+ presentations (displayed in bins of 4 stimuli) in a novel context each day of extinction training (Context B, C, D) for three days (Extinction Day 1-3). For both strains, repeated exposure to the CS+ tone in the US+ group resulted in significantly less freezing within extinction training sessions using separate 
repeated measures ANOVA per strain; effect of bin, $p<0.01)$. (D) Analysis of tone discrimination during extinction. Mice in both strains exhibited significantly more freezing when exposed to the CS+ tone $\left(D_{1}, 2\right.$-factor ANOVA; effect of $\left.C S, p<0.001\right)$. However, the C57BL/6 showed significantly better CS discrimination compared to the 12951 strain when the discrimination ratio was calculated $\left(D_{2}\right.$, unpaired t-test, $\left.p<0.0001\right)$. (E) Analysis of extinction across days (US+ Group). Freezing across extinction days was analyzed by calculating the mean percent freezing for the three binned CS+ presentations for each of the three extinction days, each in a novel context (solid line in panel C). Statistically significant reductions in freezing were observed for both C57BL/6 and $129 \mathrm{~S} 1$ mice across training sessions (main effect of training session, $p<0.0001)$. Post-hoc analysis confirmed that there were significant differences in freezing between extinction day 1 and extinction day 2 and 3 for both strains (lower asterisk, $\mathrm{p}<0.01$ ). To determine to what extent extinction learning was retained longterm, mice in both strains were randomly segregated into two groups and freezing during CS+ and CS- presentations was measured in either context B or context A (the training context) 7 days after extinction training (data to the right of the dotted line in Fig 4E). When tested 7 days after the last day of extinction training mice in both strains exhibited freezing levels that were indistinguishable from extinction training day 3 , regardless of context or strain. (F) Analysis of freezing in the US- group across days. Freezing in the US- group was calculated each day as the mean percent freezing measured during the $\mathrm{CS}+$ tone presentations (dashed line in panel C). The $129 S 1$ mice exhibited increased 'freezing' across the three days of re-exposure to the CS+ tone compared with the B6 strain $(p<0.0001)$, in spite of the fact that they never received the foot shock. Data shown as sample mean with shaded region or bars representing the 
standard error of the mean. Asterisk $\left({ }^{*}\right)$ denotes statistical significance for main effect of training (horizontal line) or strain (vertical line) and a dagger $(\dagger)$ for significant interaction between main effects. Data are presented as mean \pm SEM.

This article is protected by copyright. All rights reserved. 
Afifi, T.O. et al., 2010. The role of genes and environment on trauma exposure and posttraumatic stress disorder symptoms: a review of twin studies. Clinical psychology review, 30(1), pp.101-112.

Amano, T., Unal, C.T. \& Pare, D., 2010. Synaptic correlates of fear extinction in the amygdala. Nature Neuroscience, 13(4), pp.489-494.

An, B. et al., 2017. Amount of fear extinction changes its underlying mechanisms. eLife, 6, p.489.

Bang, S.J. \& Brown, T.H., 2009. Perirhinal cortex supports acquired fear of auditory objects. Neurobiology of Learning and Memory, 92(1), pp.53-62.

Bang, S.J. et al., 2008. Asymmetrical Stimulus Generalization following Differential Fear Conditioning. Neurobiology of Learning and Memory, 90(1), pp.200-216.

Blair, H.T. et al., 2005. The lateral amygdala processes the value of conditioned and unconditioned aversive stimuli. Neuroscience, 133(2), pp.561-569.

Camp, M. et al., 2009. Impaired Pavlovian fear extinction is a common phenotype across genetic lineages of the 129 inbred mouse strain. Genes, Brain and Behavior, 8(8), pp.744752.

Camp, M.C. et al., 2012. Genetic Strain Differences in Learned Fear Inhibition Associated with Variation in Neuroendocrine, Autonomic, and Amygdala Dendritic Phenotypes.

Neuropsychopharmacology, 37(6), pp.1534-1547.

Chhatwal, J.P. et al., 2005. Regulation of gephyrin and GABAA receptor binding within the amygdala after fear acquisition and extinction. The Journal of Neuroscience, 25(2), pp.502506.

Choi, D.C. et al., 2010. Prelimbic cortical BDNF is required for memory of learned fear but not extinction or innate fear. Proceedings of the National Academy of Sciences of the United States of America, 107(6), pp.2675-2680.

Cohen, J., 1988. Statistical power analysis for the behavioral sciences 2nd edn,

Crawley, J.N. et al., 1997. Behavioral phenotypes of inbred mouse strains: implications and recommendations for molecular studies. Psychopharmacology, 132(2), pp.107-124.

Dalton, G.L. et al., 2008. Disruption of AMPA Receptor Endocytosis Impairs the Extinction, but not Acquisition of Learned Fear. Neuropsychopharmacology, 33(10), pp.2416-2426.

Dockstader, C.L. \& van der Kooy, D., 2001. Mouse strain differences in opiate reward learning are explained by differences in anxiety, not reward or learning. The Journal of 
Neuroscience, 21(22), pp.9077-9081.

Dunsmoor, J.E. et al., 2019. Role of human ventromedial prefrontal cortex in learning and recall of enhanced extinction. Journal of Neuroscience, pp.2713-18.

Fenster, R.J. et al., 2018. Brain circuit dysfunction in post-traumatic stress disorder: from mouse to man. Nature Reviews Neuroscience, 69, p.516.

Furtak, S.C., Allen, T.A. \& Brown, T.H., 2007. Single-unit firing in rat perirhinal cortex caused by fear conditioning to arbitrary and ecological stimuli. The Journal of Neuroscience, 27(45), pp.12277-12291.

Giustino, T.F. \& Maren, S., 2015. The Role of the Medial Prefrontal Cortex in the Conditioning and Extinction of Fear. Frontiers in behavioral neuroscience, 9, pp.758-20.

Grewe, B.F. et al., 2017. Neural ensemble dynamics underlying a long-term associative memory. Nature, 543(7647), pp.670-675.

Gunduz-Cinar, O. et al., 2018. Identification of a novel gene regulating amygdala-mediated fear extinction. Molecular Psychiatry, 36, p.1.

Hefner, K. et al., 2008. Impaired fear extinction learning and cortico-amygdala circuit abnormalities in a common genetic mouse strain. The Journal of Neuroscience, 28(32), pp.8074-8085.

Herry, C. et al., 2010. Neuronal circuits of fear extinction. European Journal of Neuroscience, 31(4), pp.599-612.

Holmes, A. \& Singewald, N., 2013. Individual differences in recovery from traumatic fear. Trends in Neurosciences, 36(1), pp.23-31.

Ito, W. et al., 2009. Enhanced generalization of auditory conditioned fear in juvenile mice. Learning \& memory (Cold Spring Harbor, N.Y.), 16(3), pp.187-192.

Kar, N., 2011. Cognitive behavioral therapy for the treatment of post-traumatic stress disorder: a review. Neuropsychiatric Disease and Treatment, 7, pp.167-181.

Kessler, R.C. et al., 1995. Posttraumatic stress disorder in the National Comorbidity Survey. Archives of general psychiatry, 52(12), pp.1048-1060.

Kim, J. et al., 2007. Amygdala depotentiation and fear extinction. Proceedings of the National Academy of Sciences of the United States of America, 104(52), pp.20955-20960.

Krueger, J.N. et al., 2017. A novel mouse model of the aged brain: Over-expression of the Ltype voltage-gated calcium channel CaV1.3. Behavioural Brain Research, 322, pp.241-249.

This article is protected by copyright. All rights reserved. 
Laurent, V. \& Westbrook, R.F., 2008. Distinct contributions of the basolateral amygdala and the medial prefrontal cortex to learning and relearning extinction of context conditioned fear. Learning \& memory (Cold Spring Harbor, N.Y.), 15(9), pp.657-666.

Laurent, V. \& Westbrook, R.F., 2010. Role of the basolateral amygdala in the reinstatement and extinction of fear responses to a previously extinguished conditioned stimulus. Learning \& memory (Cold Spring Harbor, N.Y.), 17(2), pp.86-96.

Laurent, V., Marchand, A.R. \& Westbrook, R.F., 2008. The basolateral amygdala is necessary for learning but not relearning extinction of context conditioned fear. Learning \& memory (Cold Spring Harbor, N.Y.), 15(5), pp.304-314.

Likhtik, E. et al., 2008. Amygdala intercalated neurons are required for expression of fear extinction. Nature, 454(7204), pp.642-645.

Lin, C.-H., Lee, C.-C. \& Gean, P.-W., 2003. Involvement of a Calcineurin Cascade in Amygdala Depotentiation and Quenching of Fear Memory. Molecular Pharmacology, 63(1), pp.44-52.

Lin, H.-C., Mao, S.-C. \& Gean, P.-W., 2009. Block of gamma-aminobutyric acid-A receptor insertion in the amygdala impairs extinction of conditioned fear. Biological Psychiatry, 66(7), pp.665-673.

Logue, M.W. et al., 2015. The Psychiatric Genomics Consortium Posttraumatic Stress Disorder Workgroup: Posttraumatic Stress Disorder Enters the Age of Large-Scale Genomic Collaboration. Neuropsychopharmacology, 40(10), pp.2287-2297.

Loos, M. et al., 2014. Sheltering behavior and locomotor activity in 11 genetically diverse common inbred mouse strains using home-cage monitoring. PLOS ONE, 9(9), p.e108563.

MacPherson, K. et al., 2013. Temporal factors in the extinction of fear in inbred mouse strains differing in extinction efficacy. Biology of Mood \& Anxiety Disorders, 3(1), p.13.

Mao, S.-C. et al., 2013. Inhibition of Spontaneous Recovery of Fear by mGluR5 after Prolonged Extinction Training M. Baudry, ed. PLOS ONE, 8(3), p.e59580.

Martorell, A.J. et al., 2019. Multi-sensory Gamma Stimulation Ameliorates Alzheimer'sAssociated Pathology and Improves Cognition. Cell.

McKinney, B.C. \& Murphy, G.G., 2006. The L-Type voltage-gated calcium channel Cav1.3 mediates consolidation, but not extinction, of contextually conditioned fear in mice. Learning \& Memory, 13(5), pp.584-589.

McKinney, B.C., Chow, C.Y., et al., 2008. Exaggerated emotional behavior in mice heterozygous null for the sodium channel Scn8a (Nav1.6). Genes, Brain and Behavior, 7(6), pp.629-638. 
McKinney, B.C., Sze, W., et al., 2008. L-type voltage-gated calcium channels in conditioned fear: A genetic and pharmacological analysis. Learning \& Memory, 15(5), pp.326-334.

Milad, M.R. \& Quirk, G.J., 2002. Neurons in medial prefrontal cortex signal memory for fear extinction. Nature, 420(6911), pp.70-74.

Milad, M.R. et al., 2009. Neurobiological basis of failure to recall extinction memory in posttraumatic stress disorder. Biological Psychiatry, 66(12), pp.1075-1082.

Nuñez, J.R., Anderton, C.R. \& Renslow, R.S., 2018. Optimizing colormaps with consideration for color vision deficiency to enable accurate interpretation of scientific data J. Malo, ed. PLOS ONE, 13(7), p.e0199239.

Pavlov, I.P., 1927. Conditional reflexes: an investigation of the physiological activity of the cerebral cortex,

Perkowski, J.J. \& Murphy, G.G., 2011. Deletion of the mouse homolog of KCNAB2, a gene linked to monosomy $1 \mathrm{p} 36$, results in associative memory impairments and amygdala hyperexcitability. The Journal of Neuroscience, 31(1), pp.46-54.

Pitman, R.K. \& Delahanty, D.L., 2005. Conceptually driven pharmacologic approaches to acute trauma. CNS spectrums, 10(2), pp.99-106.

Quirk, G.J., Armony, J.L. \& LeDoux, J.E., 1997. Fear conditioning enhances different temporal components of tone-evoked spike trains in auditory cortex and lateral amygdala. Neuron, 19(3), pp.613-624.

Rescorla, R. \& Wagner, A., 1972. A Theory of Pavlovian Conditioning: Variations in the Effectiveness of Reinforcement and Nonreinforcement (Appletone-Century-Crofts, New York),

Singmann, H., Bolker, B. \& Westfall, J., 2015. afex: Analysis of Factorial Experiments (Version 0.13-145),

Team, R.C., 2016. R: A Language and Environment for Statistical Computing

. pp.1-2. Available at: https://www.R-project.org.

Temme, S.J. \& Murphy, G.G., 2017. The L-type voltage-gated calcium channel Ca V1.2 mediates fear extinction and modulates synaptic tone in the lateral amygdala. Learning \& memory (Cold Spring Harbor, N.Y.), 24(11), pp.580-588.

Temme, S.J. et al., 2014. Comparison of inbred mouse substrains reveals segregation of maladaptive fear phenotypes. Frontiers in behavioral neuroscience, 8, p.282. 
Tsai, L.-H. \& Gräff, J., 2014. On the resilience of remote traumatic memories against exposure therapy-mediated attenuation. EMBO reports, 15(8), pp.853-861.

Võikar, V. et al., 2001. Strain and gender differences in the behavior of mouse lines commonly used in transgenic studies. Physiology \& behavior, 72(1-2), pp.271-281.

Whittle, N. et al., 2013. Deep brain stimulation, histone deacetylase inhibitors and glutamatergic drugs rescue resistance to fear extinction in a genetic mouse model. Neuropharmacology, 64, pp.414-423.

Whittle, N. et al., 2016. Enhancing dopaminergic signaling and histone acetylation promotes long-term rescue of deficient fear extinction. Translational Psychiatry, 6(12), pp.e974-e974.

Whittle, N. et al., 2010. Rescue of impaired fear extinction and normalization of corticoamygdala circuit dysfunction in a genetic mouse model by dietary zinc restriction. The Journal of Neuroscience, 30(41), pp.13586-13596.

Wickham, H., 2010. ggplot2: elegant graphics for data analysis (Use R!),

Wickham, H. et al., 2015. dplyr: A Grammar of Data Manipulation (version 0.4. 3), 
A.
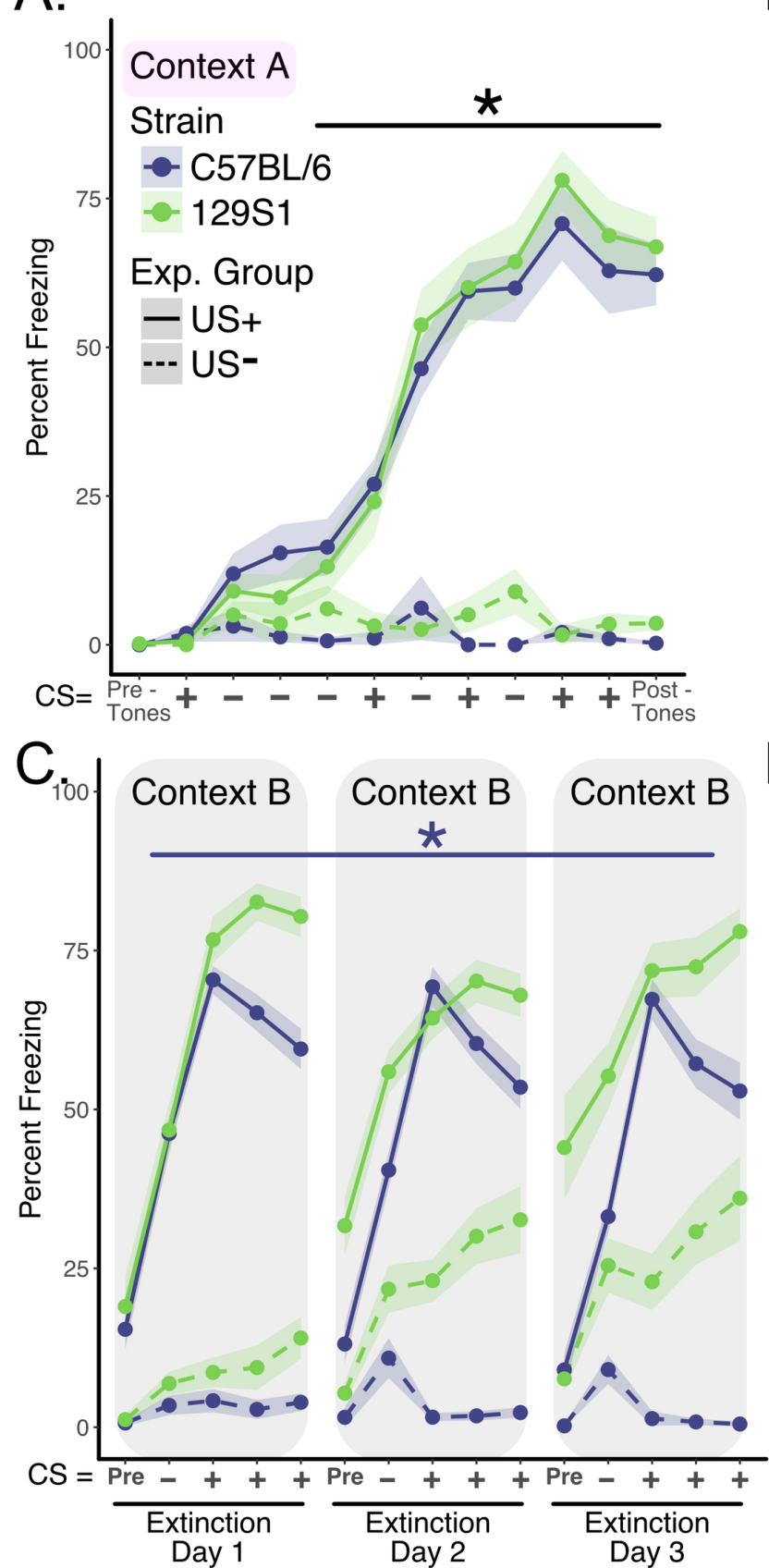

E.

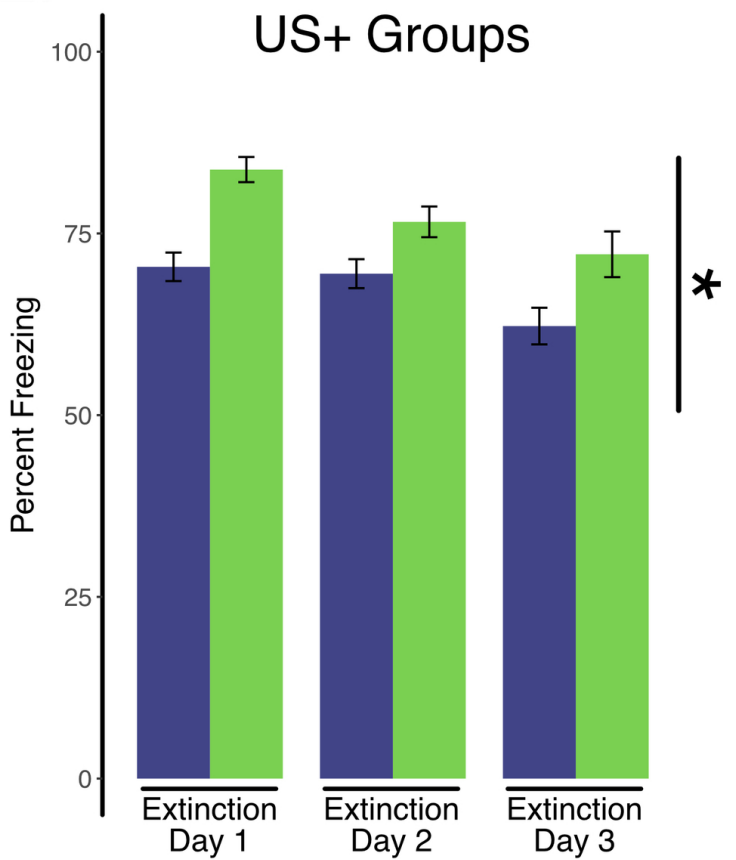

B

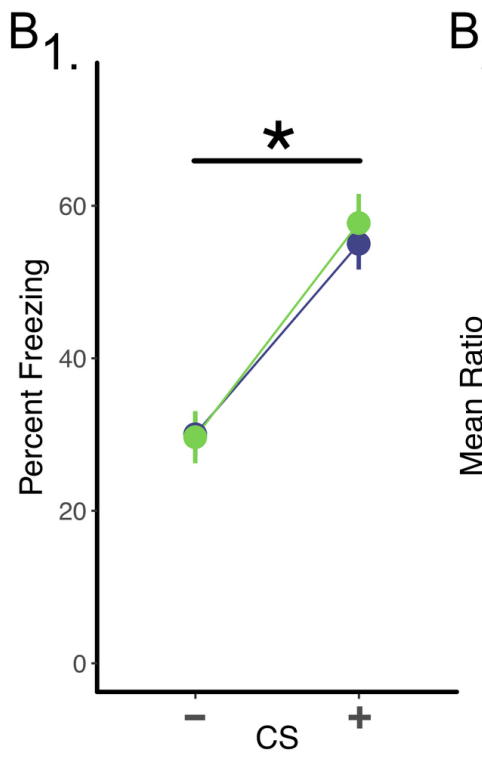

$B_{2}$.

D.

$\mathrm{D}_{1}$

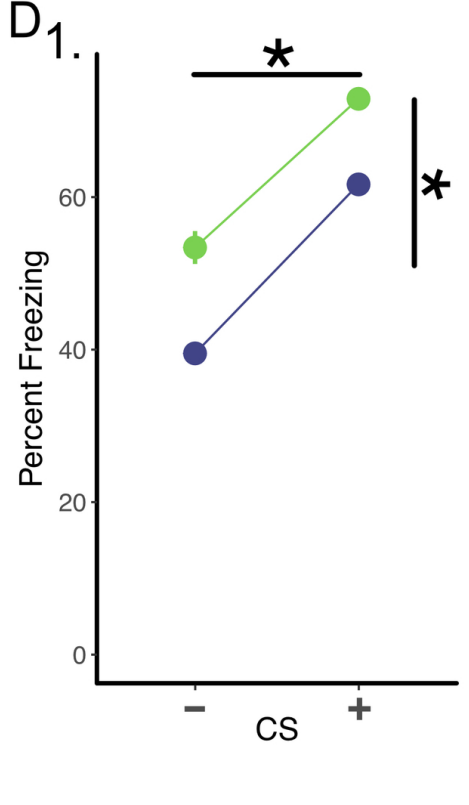

$D_{2}$

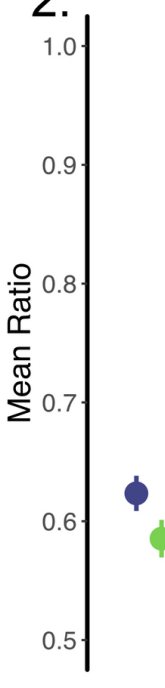

F.

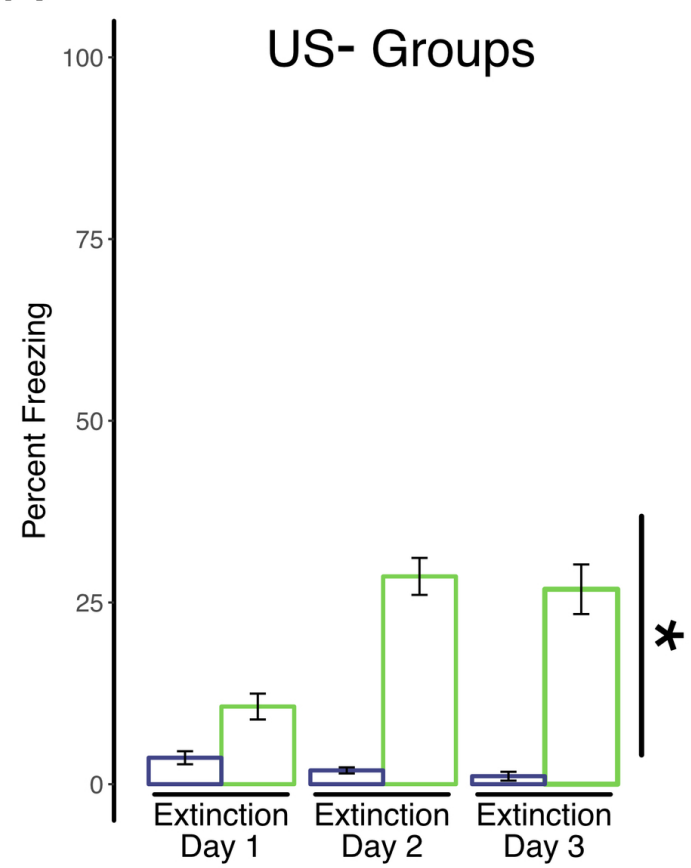

GBB_12575_Figure 1v3.jpg

This article is protected by copyright. All rights reserved. 
A.

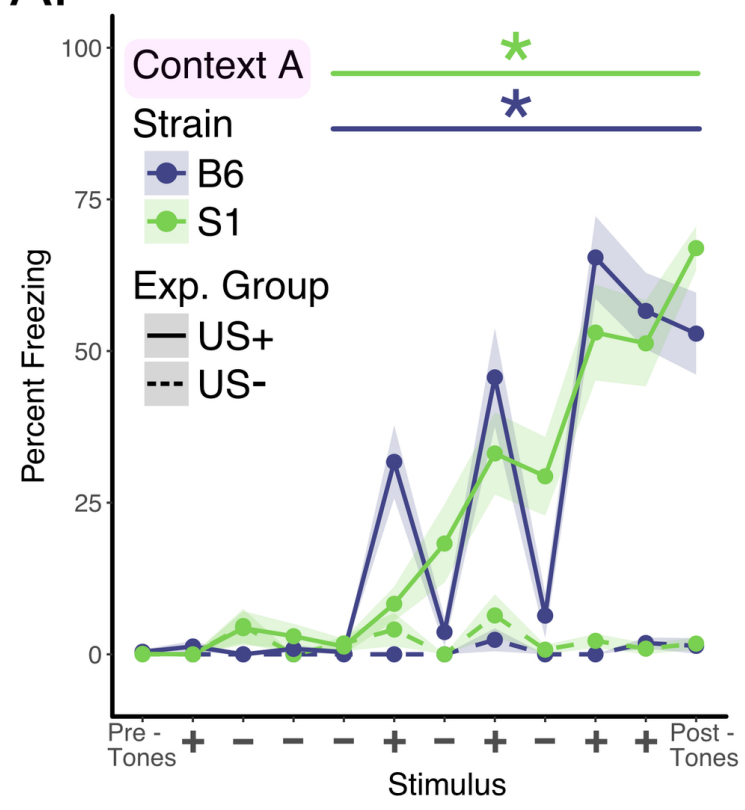

C.

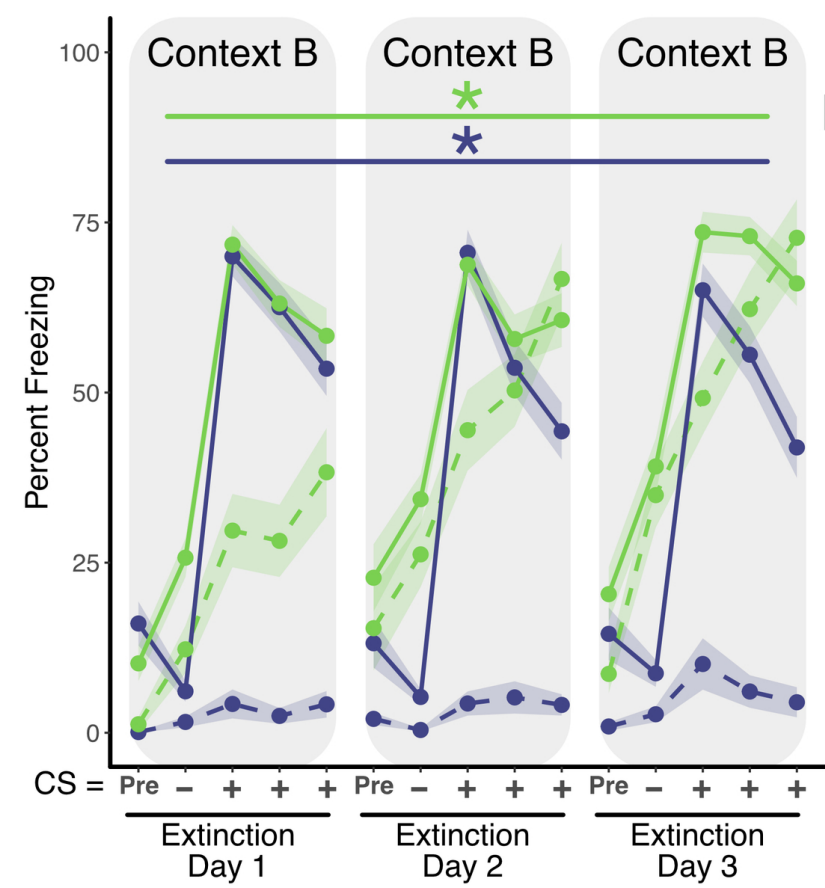

E.

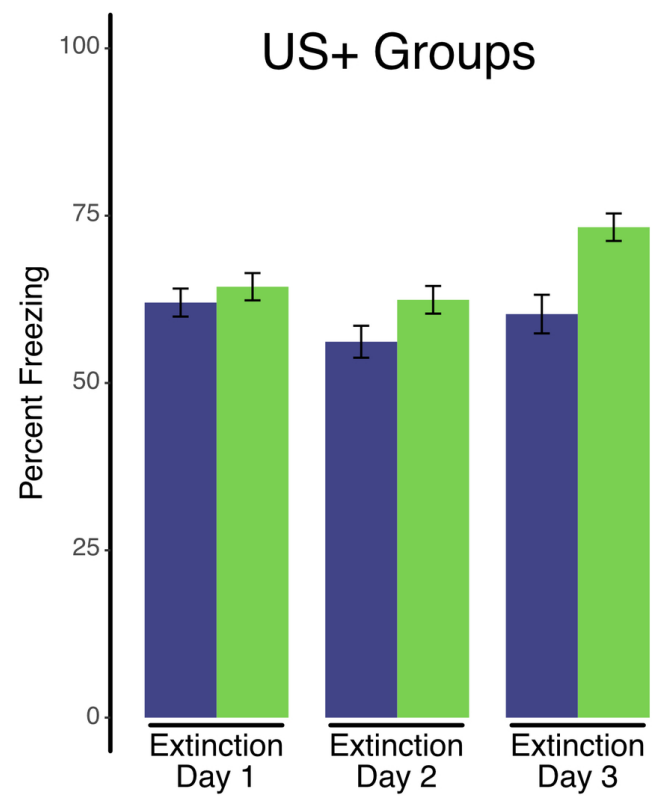

B.
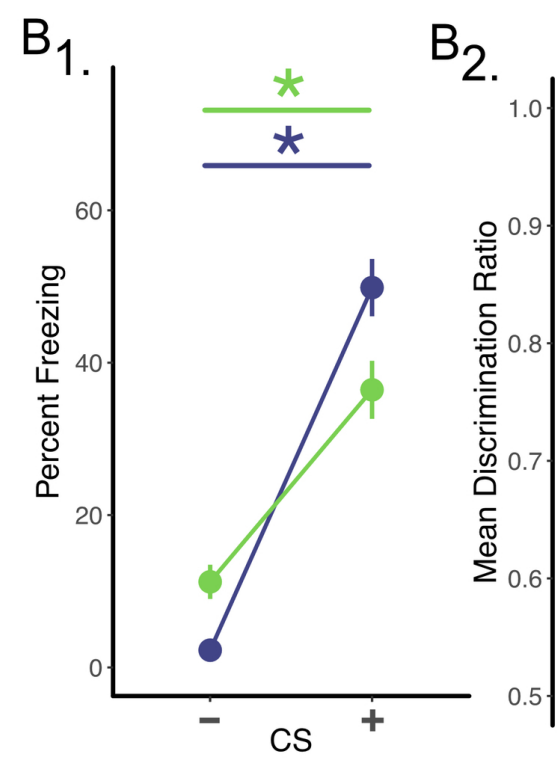

D.

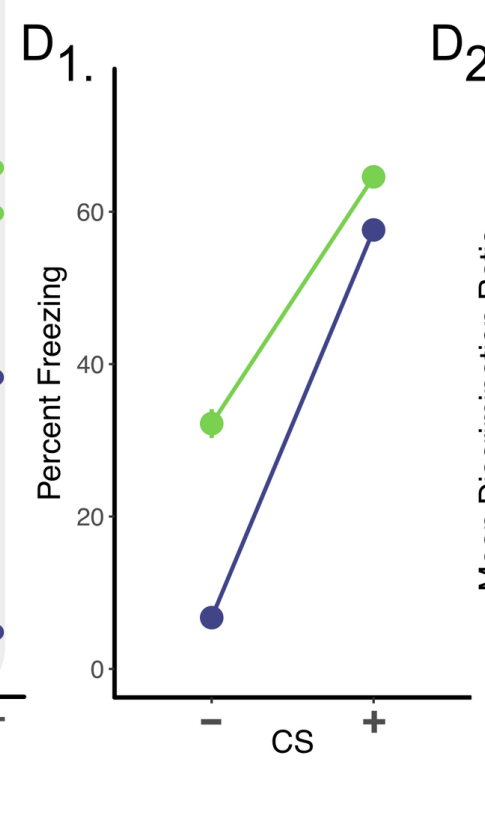

$D_{2}$

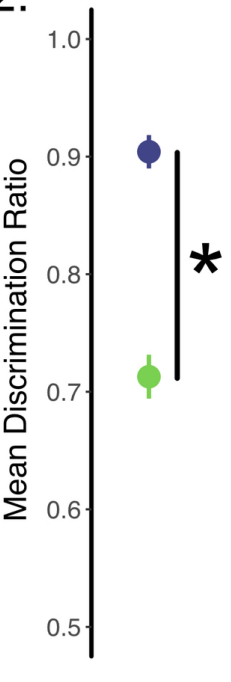

F.

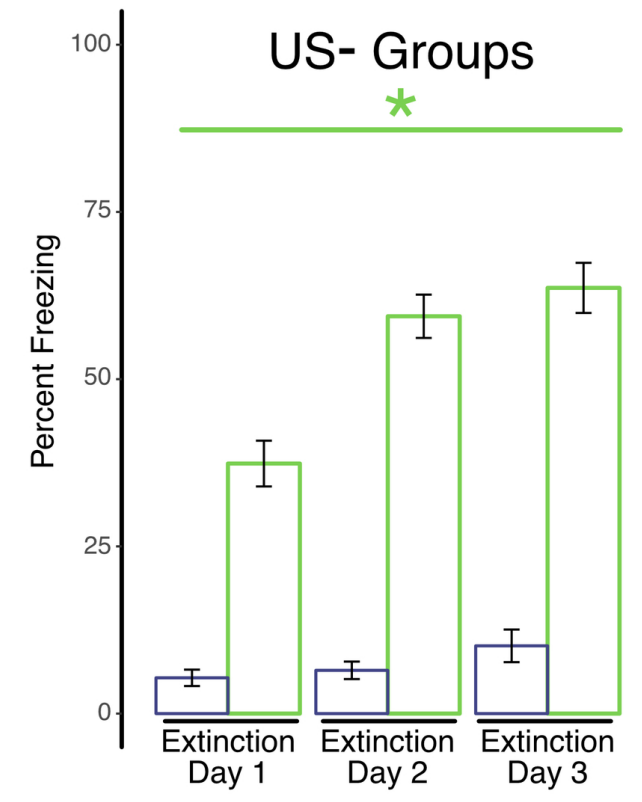

GBB_12575_Figure 2v3.jpg

This article is protected by copyright. All rights reserved. 
A.

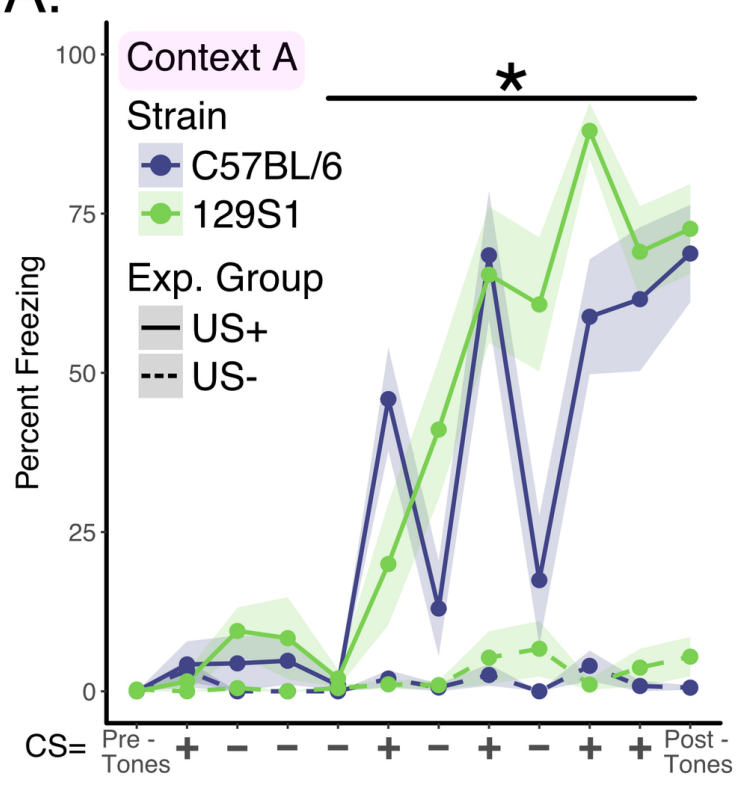

C.

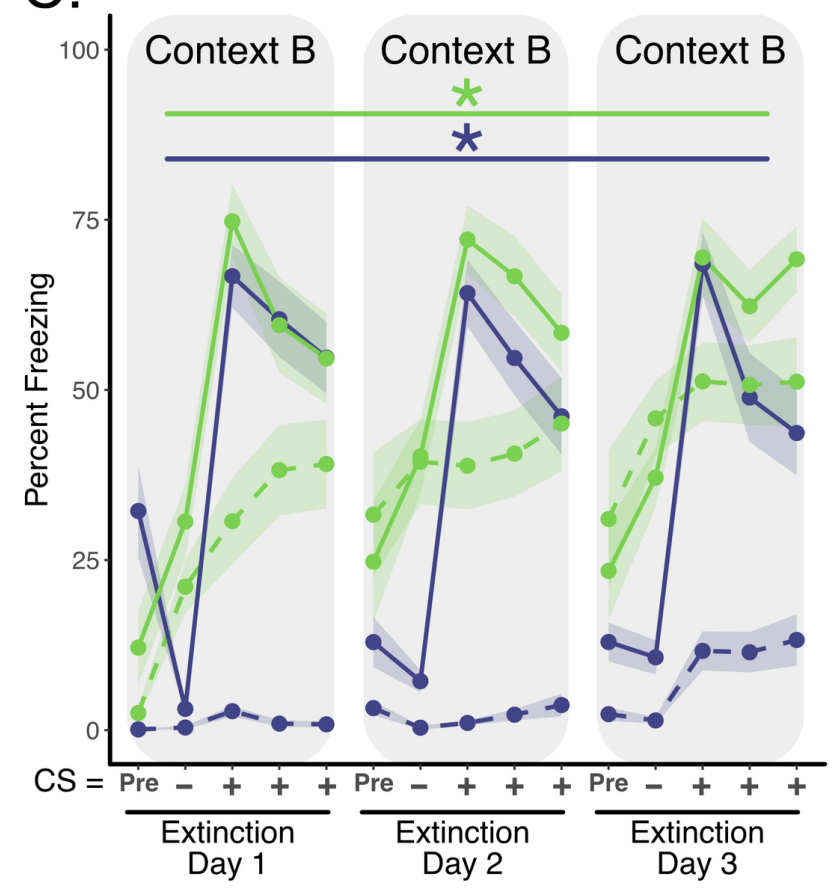

E.

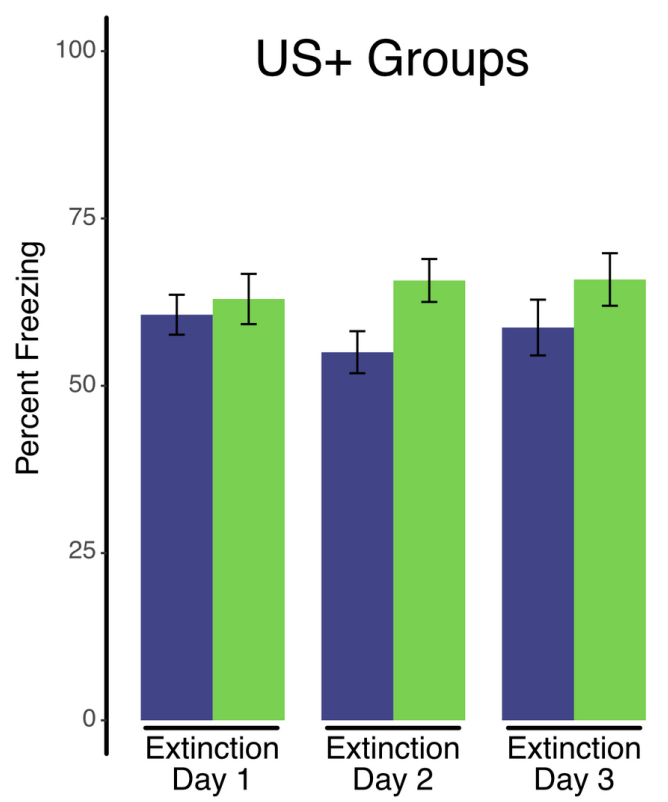

B.

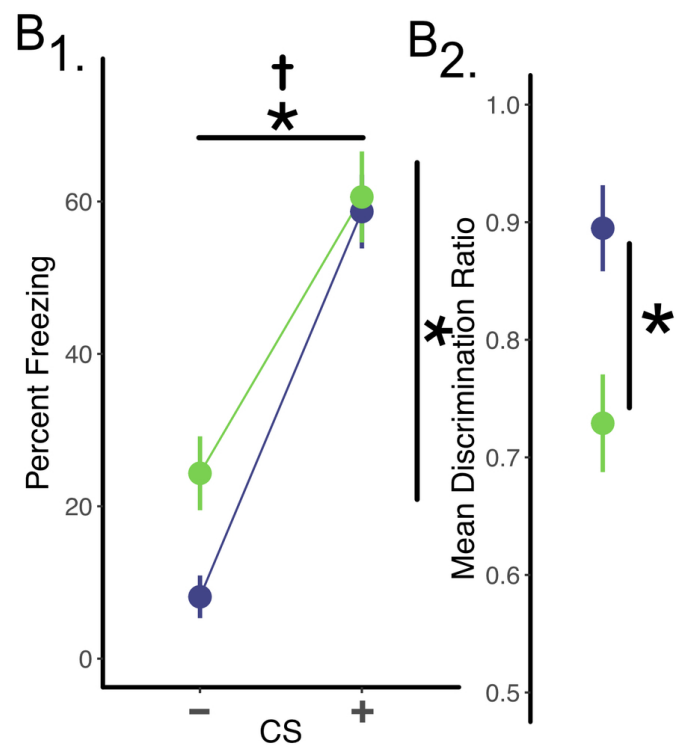

D.

$D_{1}$

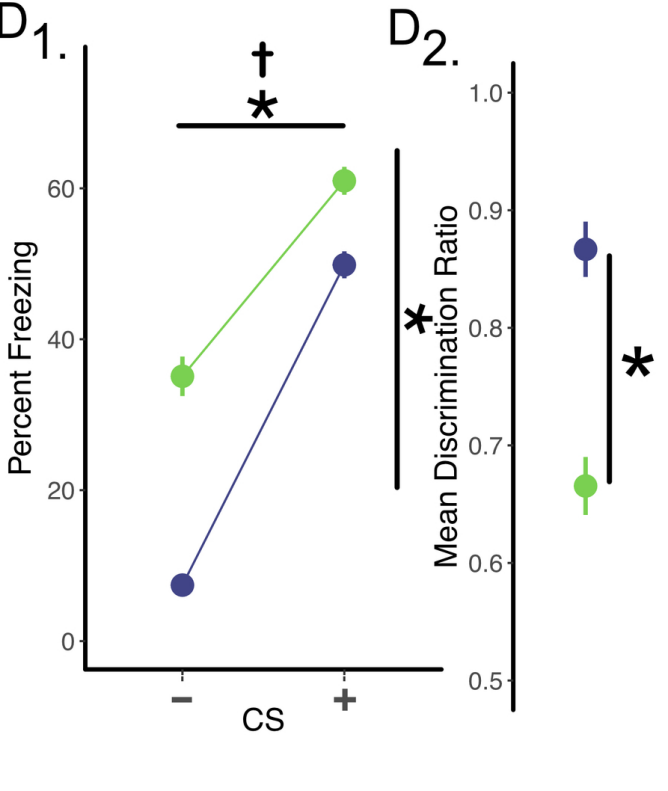

F.

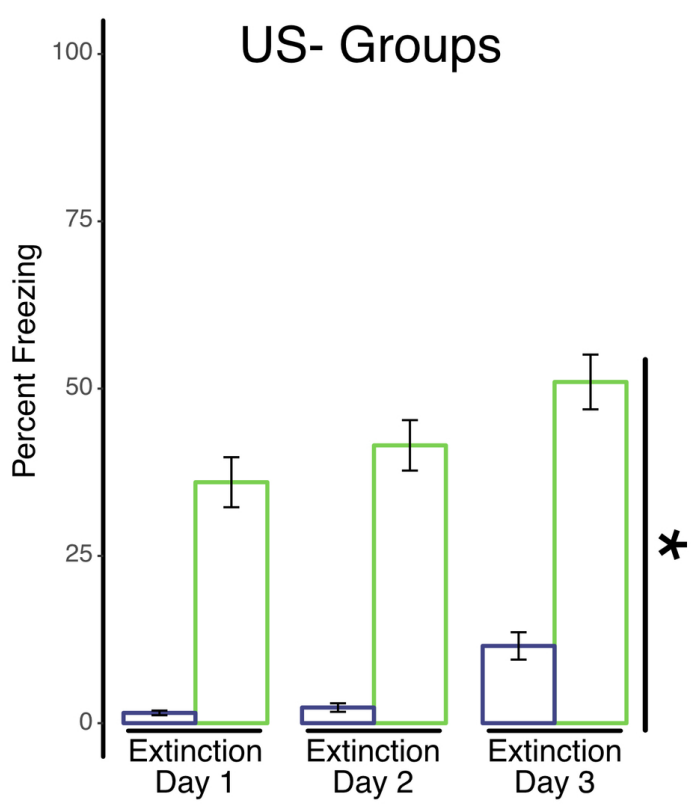

GBB_12575_Figure 3v3.jpg

This article is protected by copyright. All rights reserved. 

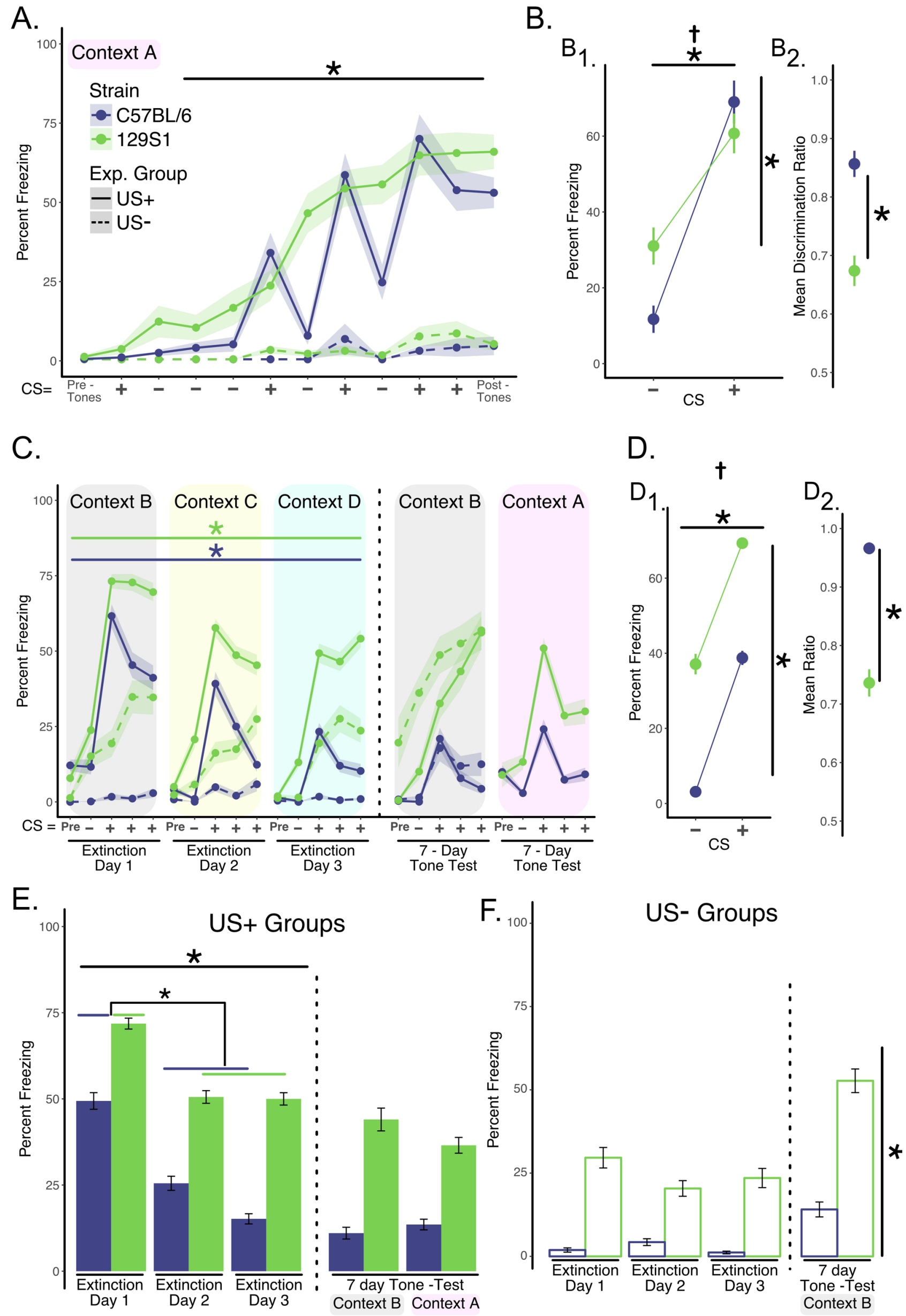

GBB_12575_Figure 4v3.jpg

This article is protected by copyright. All rights reserved. 